\title{
FAKTOR YANG MEMPENGARUHI ORGANIZATIONAL CITIZENSHIP BEHAVIOR (OCB) BADAN USAHA MILIK DESA
}

\author{
Muhammad Hengki Setiawan ${ }^{1}$ \\ ${ }^{1}$ Universitas Sarjanawiyata Tamansiswa Yogyakarta \\ hengkysetiawan797@gmail.com \\ Prayekti $^{2}$ \\ ${ }^{2}$ Universitas Sarjanawiyata Tamansiswa Yogyakarta \\ yekti_feust@yahoo.co.id \\ Ignatius Soni Kurniawan ${ }^{3}$ \\ ${ }^{3}$ Universitas Sarjanawiyata Tamansiswa Yogyakarta \\ Soni_kurniawan@ustjogja.ac.id
}

\begin{abstract}
This study examines the mediation of internal motivation on the influence of individual characteristics and affective commitment to Organizational Citizenship Behavior (OCB) BUMDes Panggung Lestari employees. A total of 103 BUMDes Panggung Lestari employees, Panggungharjo Village, Sewon District, Bantul Regency became the population in this study. The sampling technique uses accidental sampling with data collection using a questionnaire. The findings prove that individual characteristics positively influence intrinsic motivation but do not affect $O C B$. Affective commitment does not affect intrinsic motivation but affects $O C B$. Research shows that internal motivation mediates the effect of individual characteristics on $O C B$. The findings can provide managerial considerations regarding the antecedents of $O C B$.
\end{abstract}

Keywords: Individual Characteristics; Affective Commitment; Intrinsic Motivation; organizational; Citizenship behavior

Abstrak: Penelitian ini menguji mediasi motivasi internal pada pengaruh karakteristik individu dan komitmen afektif terhadap Organizational Citizenship Behavior (OCB) karyawan BUMDes Panggung Lestari. Sebanyak 103 karyawan BUMDes Panggung Lestari, Desa Panggungharjo, Kecamatan Sewon, Kabupaten Bantul menjadi populasi dalam penelitian ini. Teknik pengambilan sampel menggunakan accidental sampling dengan pengumpulan data menggunakan kuesioner. Temuan membuktikan bahwa karakteristik individu secara positif mempengaruhi motivasi intrinsik tetapi tidak mempengaruhi OCB. Komitmen afektif tidak mempengaruhi motivasi intrinsik tetapi mempengaruhi OCB. Penelitian menunjukkan bahwa motivasi internal memediasi pengaruh karakteristik individu pada OCB. Temuan ini dapat memberikan pertimbangan manajerial tentang anteseden OCB.

Kata kunci: Karakteristik Individu; Komitmen Afektif; Motivasi Intrinsik; organisasi; Citizenship behavior. Article History: Received 2020-03-07; Revised 2020-04-08; Accepted 2020-04-13

\section{PENDAHULUAN}

Salah satu ukuran yang digunakan untuk melihat keberhasilan suatu Negara dalam perekonomian adalah peningkatan kesejahteraan rakyatnya. Pemerintah mengusahakan 
pembangunan perekonomian desa dengan harapan mampu mendorong perkembangan Usaha Mikro Kecil Menengah (UMKM) sebagai basis penghidupan rakyat. Secara khusus Badan Usaha Milik Desa (BUMDes) menjadi fokus sasaran pengembangan karena bersifat resiprosikal yaitu warga desa mengembangkan potensi desanya sendiri untuk kesejahteraan ekonomi warga desa itu sendiri. Salah satu BUMDes yang memiliki prestasi adalah BUMDes Panggung Lestari yang berada di Desa Panggungharjo, Kecamatan Sewon, Kabupaten Bantul, Daerah Istimewa Yogyakarta. BUMDes Panggung Lestari membangun pengolahan minyak nyamplung untuk dijadikan obat-obatan, rumah makan Kampung Mataraman yang berkonsep desa, serta rumah pengelolaan sampah. Adapun rumah pengelolaan sampah telah menjadikan BUMDes Panggung Lestari sebagai BUMDes percontohan ditingkat nasional. Menarik untuk dikaji mengapa karyawan BUMDes Panggung Lestari mengabdikan diri (Organizational Citizenship Behavior) bagi kemajuan desanya melalui BUMDes.

Organizational Citizenship Behavior (OCB) menurut Romaiha et al., (2019) ditentukan oleh conscientiousness dan altruism. Altruism yang dapat diartikan sebagai individu yang peduli dengan kesejahteraan orang lain penting dimiliki pada diri karyawan ketika ingin memajukan organisasi. Demikian juga orang dengan conscientiousness merupakan pribadi yang bertanggungjawab dan dapat dipercaya untuk menyelesaikan usaha dengan keras. BUMDes yang memiliki karyawan dengan karakteristik individu conscientiousness dan altruism akan menentukan intensitas OCB dari anggotanya. Hal ini menguntungkan karena karakteristik individu merupakan suatu yang melekat pada diri karyawan dan lebih sulit diubah atau relatif stabil (Purba \& Seniati, 2004).

Individu yang ingin memajukan desanya dengan penyebab karena ia tinggal di desa tersebut dan telah memiliki hubungan sosial merupakan bentuk dari keterikatan afektif. Benjamin (2012) mendukung pemahaman tersebut, bahwa komitmen afektif merupakan pendukung terciptanya OCB. Dengan demikian seharusnya BUMDes maju karena para karyawannya adalah warga desa itu sendiri, namun Ihsanuddin (2019) dalam tulisannya di Kompas menyatakan banyak BUMDes di Indonesia tidak beroperasi dan belum berkontribusi bagi pendapatan desa. Perilaku OCB perlu diuji apakah muncul dengan sendirinya hanya karena seseorang memiliki karakteristik sifat pekerja dan karena ia punya komitmen afektif atau perlu variabel pemediasi. Motivasi karyawan untuk memajukan BUMDes diajukan sebagai pemediasi karakteristik personal dan komitmen untuk memunculkan OCB dalam penelitian ini.

Penelitian Romaiha et al., (2019) menemukan bahwa motivasi intrinsik dan ekstrinsik merupakan anteseden dari OCB, lebih lanjut dinyatakan bahwa motivasi intrinsik merupakan penentu terkuat. Demikian juga dengan Barabuto Jr. \& Story (2012) dalam studi lapangannya yang menegaskan adanya pengaruh positif dari konsep diri motivasi internal terhadap OCB. Penelitian ini menjadi penting bagi pengelola BUMDes Panggung Lestari untuk memahami apa penyebab OCB pada karyawannya.

\section{KAJIAN TEORI}

Kepribadian seseorang relatif stabil atau relatif tidak berubah (Beli \& Njoli, 2016) namun menurut Wahyudi \& Prawita (2014) kepribadian dapat berubah sebagai bentuk penyesuaian terhadap kondisi lingkungan. Kepribadian dibagi oleh Bhatti, Kaur, \& Battour (2013) berupa ekstroversi, kesesuaian, kesadaran, neurotisme, dan keterbukaan. Lebih lanjut Rothmann \& Coetzer (2003) menyatakan terdapat lima faktor dalam kepribadian yang mengarahkan pada kesuksesan yaitu low neuroticism, extraversion, openness to experience, agreeableness, dan conscientiousness.

Komitmen afektif karyawan didefinisikan sebagai sikap loyalitas karyawan terhadap organisasinya agar organisasi terus berkembang dan karyawan juga dapat berprestasi untuk mencapai karier yang lebih tinggi (Lee et al., 2013). Komitmen afektif menurut Allen \& Meyer

Muhammad Hengki Setiawan1, Prayekti2, I.Soni Kurniawan3 - Faktor Yang Mepengaruhi Organizational Citizenship Behavior ...

[Vol 11, No 1 (2020): April 2020] JBTI 
(1990) merupakan suatu pola pikir atau keadaan psikologis yang dapat mencerminkan keinginan (komitmen afektif), kebutuhan (komitmen kontinuan), dan kewajiban (komitmen normatif) karyawan untuk mempertahankan keanggotaannya pada sebuah organisasi. Komitmen afektif menunjukkan keterikatan karyawan pada organisasi yang didasarkan pada identifikasinya pada organisasi, sehingga mengarahkan karyawan untuk berperilaku positif, seperti keinginan meraih tujuan organisasi, menurunnya tingkat absensi dan turnover, serta mempengaruhi resistensi karyawan (Munajah \& Purba, 2018). Komitmen afektif terjadi apabila karyawan merasa memiliki ikatan emosional dengan organisasi berupa perasaan bahagia berada dalam organisasi dan memiliki arti penting menjadi bagian dari organisasi (Mulyadi, Kamaluddin, \& Maharani, 2019). Karyawan harus memiliki dedikasi dan mampu bekerja sama dengan baik agar organisasi tetap maju, selain itu organisasi juga harus mengontrol apa yang dibutuhkan karyawan agar tetap memiliki komitmen terhadap perusahaan (Munajah \& Purba, 2018).

Motivasi intrinsik merupakan dorongan yang ada dalam diri individu untuk melakukan sesuatu yang berguna demi mencapai tujuan yang diinginkan (Puspitasari, 2019). Menurut Oren, Tziner, Nahshon, \& Sharoni (2013) motivasi merupakan seperangkat kekuatan energik yang timbul dalam diri individu sendiri yang dipengaruhi lingkungannya untuk memulai perilaku yang berhubungan dengan pekerjaan, dan untuk menentukan intensitas dan durasi. Kurniawan \& Hutami (2019) menyatakan bahwa memberikan penghargaan tinggi dan pengakuan pada karyawan akan dapat meningkatkan keterlibatan kerja serta OCB karyawan, manajemen penghargaan perlu dilakukan pada tingkat bisnis yang bergerak pada sektor UKM karena pada umumnya UKM mengalami keterbatasan dibandingkan dengan perusahaan besar. Pengembangan motivasi karyawan adalah satu cara untuk meningkatkan kinerja yang lebih tinggi bagi karyawan untuk menghasilkan peningkatan kualitas (Drake, Wong, \& Salter, 2007).

OCB karyawan diwujudkan melalui mudah berkolaborasi dengan lingkungan pekerjaan, melakukan pekerjaan secara sukarela tanpa mengharapkan adanya imbalan dari organisasi, mengurangi perselisihan, dan meningkatkan efisiensi pada organisasi (Nazmah, Mariatin, \& Supriyantini, 2018). Faktor-faktor yang mempengaruhi OCB adalah motivasi kerja dan keadilan organisasi (Nazmah et al., 2018). Kurniawan \& Hutami (2019) menggunakan sudut pandang konsep OCB yang mudah diterapkan pada organisasi UKM melalui penekanan pentingnya mengusahakan pekerja untuk berkontribusi bagi perusahaan dan perilaku ekstra karyawan secara bersama-sama bekerja yang dapat meningkatkan efektifitas organisasi. Kurniawan, (2019) menyarankan organisasi untuk selalu menanamkan nilai perusahaan kepada karyawan untuk terlibat secara kognitif (ngerti), afektif (ngroso), dan fisik (nglakoni) untuk meningkatkan kinerja. OCB diharapkan mampu berkembang serta menjadi penyintas BUMDes dari persaingan.

\section{Pengembangan Hipotesis}

Karakteristik individu didalam organisasi terdiri atas kemampuan, keterampilan, pengalaman, latar belakang, dan demografi individu yang bersangkutan. Dessler (2013) membagi karakteristik individu ke dalam beberapa bagian yaitu minat, jati diri, kepribadian, dan latar belakang sosial. Kridharta \& Rusdianti (2017) menyatakan bahwa karakteristik individu menunjukkan perbedaan karakter tentang motivasi, inisiatif, dan kemampuan untuk tetap tegar menghadapi permasalahan yang harus diselesaikan. Lebih lanjut dinyatakan bahwa karakteristik individu secara langsung berpengaruh terhadap motivasi, apabila karakteristik individu setiap karyawan baik maka akan mempengaruhi motivasi individu untuk terus berperilaku baik dan bekerja dengan baik di dalam organisasi (Kridharta \& Rusdianti, 2017). Kepribadian pada emosi yang stabil berpengaruh pada motivasi dibanding yang agresif (Nuckcheddy, 2018). Major, Turner, \& Fletcher (2006) menunjukkan pengaruh positif karakteristik individu terhadap motivasi intrinsik.

H1: Karakteristik individu berpengaruh positif terhadap motivasi intrinsik.

Muhammad Hengki Setiawan1, Prayekti2, I.Soni Kurniawan3 - Faktor Yang Mepengaruhi Organizational Citizenship Behavior ... [Vol 11, No 1 (2020): April 2020] JBTI 
Jaros (2007) mendefinisikan komitmen afektif sebagai keterikatan emosional karyawan dengan organisasi yang muncul dari individu untuk tetap bertahan dalam organisasi. Karyawan yang memiliki komitmen akan berupaya memenuhi kebutuhan pribadinya melalui usaha memperbaiki organisasi agar mencapai tujuan yang yang harus dipenuhi. Murgianto, Sulasmi, \& Suhermin (2016) menemukan komitmen berpengaruh positif terhadap motivasi. Pada bidang pendidikan komitmen juga ditemukan berpengaruh positif terhadap motivasi tenaga kependidikan (Farida, Iqbal, \& Kurniasih, 2016), demikian juga Safrizal (2014) menemukan hal yang senada pada bidang lain.

H2: Komitmen afektif berpengaruh positif terhadap motivasi intrinsik.

Karakteristik individu adalah sifat dasar yang melekat pada individu meliputi karakteristik demografis (latar belakang keluarga, pengalaman, dan usia) serta karakteristik psikologis yang terdiri dari sikap, kepribadian, pembelajaran, dan motivasi (Saragih, Sinulingga, \& Siahaan, 2019). Zehir, Muceldili, \& Zehir (2012) menyatakan OCB memberikan hasil yang positif bagi organisasi, meningkatkan produktifitas kinerja organisasi, serta memudahkan koordinasi kegiatan antar tim dan kelompok kerja. Lee et al. (2013) menyatakan OCB sebagai perilaku karyawan yang mau melakukan pekerjaan diluar tugas utamanya, perilaku dan sikap karyawan ini sangat membantu organisasi untuk berkembang. Darsana (2013) dan Leephaijaroen (2016) menunjukkan dalam risetnya bahwa personality secara langsung berpengaruh positif terhadap OCB.

H3: Karakteristik individu berpengaruh positif terhadap OCB.

Karyawan dengan komitmen afektif yang tinggi akan lebih kuat dalam alasannya untuk meningkatkan kinerja. Zehir et al., (2012) menemukan pengaruh positif komitmen (afektif dan kontinuan) terhadap OCB. Bentuk sikap OCB karyawan dapat ditunjukkan dengan membantu rekan kerja yang kelebihan beban, sukarela membuat tugas organisasi, dan mengembangkan keterampilan yang bermanfaat bagi organisasi. Meskipun demikian Podsakoff, MacKenzie, Paine, \& Bachrach (2000) melihat masih tumpang tindihnya konsep in-role dan extra-role yang perlu dikaji lagi. Adanya pengaruh positif komitmen afektif terhadap OCB dibuktikan oleh Allen, Evans, \& White (2011).

H4: Komitmen afektif berpengaruh positif terhadap OCB.

Motivasi muncul dari kebutuhan fisik atau psikologis yang belum terpenuhi, kebutuhan ini dapat memunculkan kesadaran pentingnya manfaat dari pekerjaan (Nazmah et al., 2018). Karyawan yang memiliki motivasi intrinsik yang tinggi akan memiliki kekuatan energi yang timbul dalam diri individu untuk menyukai pekerjaan dan berpengaruh pada sikap OCB (Oren, Tziner, Nahshon, \& Sharoni, 2013). Bentuk sikap OCB sendiri tidak berkaitan dengan sistem reward formal dalam organisasi tetapi memiliki dampak signifikan dalam meningkatkan efektivitas organisasi (Drake, Wong, \& Salter, 2007). Penelitian yang dilakukan Part (2010), Ibrahim \& Aslinda (2015), dan Nazmah et al. (2018) menyatakan bahwa motivasi intrinsik berpengaruh positif terhadap OCB.

H5: Motivasi intrinsik berpengaruh positif terhadap OCB.

Kridharta \& Rusdianti, (2017) menemukan pengaruh karakteristik individu terhadap motivasi, sementara Ibrahim \& Aslinda (2015) membuktikan motivasi berpengaruh terhadap OCB, temuan keduanya dapat digabung menjadi bentuk mediasi. Karyawan dengan karakteristik tertentu cenderung memiliki energi dan motivasi untuk memenuhi kebutuhannya. Karyawan yang memiliki motivasi akan bekerja secara bertanggung jawab dan akan membentuk loyalitas pada diri karyawan untuk bekerja (Nazmah et al., 2018). Loyalitas tersebut ditunjukkan dengan sikap karyawan untuk mengikuti aturan dalam organisasi, dan bersikap altruism yang berarti karyawan berperilaku suka rela membantu orang lain dalam bekerja (Lee et al., 2013) sehingga memberikan manfaat dan keuntungan bagi organisasi.

H6: Motivasi intrinsik memediasi pengaruh karakteristik individu terhadap OCB.

Muhammad Hengki Setiawan1, Prayekti2, I.Soni Kurniawan3 - Faktor Yang Mepengaruhi Organizational Citizenship Behavior ... [Vol 11, No 1 (2020): April 2020] JBTI 
Zehir et al., (2012) mengemukakan karyawan dengan komitmen akan terdorong untuk melampaui tugas yang ditentukan, komitmen pada tim juga berpengaruh positif pada internal entrepreneurship yang mempengaruhi orang-orang dalam perusahaan secara keseluruhan. Penelitian Farida et al., (2016) menemukan efek positif dari komitmen terhadap motivasi, sementara Part (2010) serta Ibrahim \& Aslinda (2015) menemukan motivasi berpengaruh terhadap OCB. Adanya komitmen akan mendorong motivasi intrinsik pada diri individu dan menghasilkan OCB yang tinggi pada karyawan. OCB kadang-kadang disebut sebagai perilaku pro-sosial, perilaku extra-role atau kinerja kontekstual (Zehir et al., 2012).

H7: Motivasi intrinsik memediasi pengaruh komitmen afektif terhadap OCB.

\section{METODE PENELITIAN}

Penelitian ini menggunakan seluruh karyawan BUMDes Panggung Lestari, Desa Panggungharjo dengan jumlah 103 Karyawan sebagai populasi. Mengacu pada Rumus Slovin (Sevilla, 1960) untuk ukuran populasi 103 maka sampel yang digunakan adalah 82 responden. Teknik pengambilan sampel menggunakan accidental sampling. Metode analisis data menggunakan analisis regresi linier berganda dan Sobel test.

$$
\begin{aligned}
& n=\frac{N}{1+N e^{2}} \\
& n=\frac{103}{1+103 \cdot 0,05^{2}} \\
& n=81,9 \\
& \text { Dibulatkan menjadi } 82 \text { karyawan. }
\end{aligned}
$$

Keterangan: $n=$ Ukuran sampel; $N=$ Populasi; $e=$ Nilai presisi (tingkat kepercayaan $95 \%$ maka error 5\%).

\section{Tabel 1. Indikator}

\begin{tabular}{|l|l|}
\hline \multicolumn{1}{|c|}{ Variabel } & \multicolumn{1}{|c|}{ Indikator } \\
\hline Karakteristik individu & 1. Neurotic \\
& 2. Extraversion \\
& 3. Openness to Experience \\
& 4. Agreeableness \\
\hline Komitmen Afektif & 1. Loyalitas \\
(Allen \& Meyer, 1990) & 2. Tanggung jawab \\
& 3. Emotional \\
\hline Motivasi Intrinsik & 4. Kepercayaan dan penerimaan \\
(Hamzah, 2009) & 1. Kebutuhan Apresiasi \\
& 2. Kebutuhan Tantangan Tugas \\
& 3. Kebutuhan bekerja lebih baik \\
& 4. Kebutuhan bekerja sama \\
& 5. Kebutuhan untuk terlibat penting dalam organisasi \\
& 6. Kebutuhan hubungan baik dengan rekan kerja \\
& 7. Kebutuhan untuk ikut proses pengambilan keputusan \\
\hline Organization Citizenship Behavior & 8. Kebutuhan memberi arahan \\
(Organ \& Ryan, 1995) & 1. Sebutuhan untuk memimpin \\
\hline & 2. Courtsmanship \\
& 3. Altrusim \\
\hline
\end{tabular}

\section{HASIL DAN PEMBAHASAN}

Item uji validitas dikatakan valid jika nilai $r$ hitung $\geq \mathrm{r}$ tabel $(0,1829)$. Pengujian pearson correlation menghasilkan $r$ hitung karakteristik individu (0,240 s.d. 0,547), komitmen afektif $(0,273$ 
s.d 0,642), motivasi intrinsik $(0,246$ s.d. 0,457$)$, dan $O C B(0,228$ s.d. 0,476$)>0,1829$ atau valid. Cronbach's Alpha Based on Standardized Items karateristik individu (0,680), komitmen afektif $(0,746)$, motivasi intrinsik $(0,673)$, dan $\operatorname{OCB}(0,676)>0,6$ atau instrumen reliabel.

Tabel 2. Karakteristik Responden

\begin{tabular}{|c|c|c|c|}
\hline & Karakteristik & Frequency & Percent \\
\hline \multirow[t]{2}{*}{ Jenis Kelamin } & Laki-laki & 51 & 62,2 \\
\hline & Perempuan & 31 & 37,8 \\
\hline \multirow[t]{5}{*}{ Usia } & Kurang dari 20 Tahun & 4 & 4,9 \\
\hline & 20 Tahun -30 Tahun & 32 & 39,0 \\
\hline & 31 Tahun - 40 Tahun & 14 & 17,1 \\
\hline & 41 Tahun -50 Tahun & 24 & 29,3 \\
\hline & Diatas 50 Tahun & 8 & 9,8 \\
\hline \multirow[t]{4}{*}{ Pendidikan } & SD/Sederajat & 12 & 14,6 \\
\hline & SLTP/ Sederajat & 28 & 34,1 \\
\hline & SLTA/ Sederajat & 30 & 36,6 \\
\hline & $\mathrm{S} 1 / \mathrm{S} 2 / \mathrm{S} 3$ & 12 & 14,6 \\
\hline \multirow{3}{*}{$\begin{array}{l}\text { Membutuhkan kreatifitas } \\
\text { tinggi }\end{array}$} & $\mathrm{Ya}$ & 66 & 80,5 \\
\hline & Cukup Membutuhkan & 14 & 17,1 \\
\hline & Tidak & 2 & 2,4 \\
\hline
\end{tabular}

Karakteristik responden menunjukkan bahwa sebagian besar responden adalah laki-laki $(62,2 \%)$. Berdasar usia, mayoritas responden berumur 20-30 tahun (39,0\%), sedangkan menurut tingkat pendidikan mayoritas adalah lulusan SLTA/Sederajat (36,6\%). Sebanyak 80,5\% responden menyatakan pekerjaannya menuntut kreatifitas tinggi, dan hanya $2 \%$ yang menyatakan tidak dibutuhkan kreatifitas tinggi.

Tabel 3. Asumsi Klasik

\begin{tabular}{|c|c|c|c|c|c|c|c|}
\hline \multirow{2}{*}{ Model } & \multicolumn{2}{|c|}{ Variabel } & Normalitas & \multicolumn{2}{|c|}{ Heteroskedastisitas } & \multicolumn{2}{|c|}{ Multikolonieritas } \\
\hline & Bebas & Terikat & Asymp. Sig. & $t$. & Sig. & Tol. & VIF \\
\hline \multirow{2}{*}{1} & KI & \multirow{2}{*}{ MI } & \multirow{2}{*}{0,75} & 0,427 & 0,673 & 0,990 & 1,010 \\
\hline & KA & & & $-1,225$ & 0,232 & 0,990 & 1,010 \\
\hline \multirow{3}{*}{2} & KI & \multirow{3}{*}{ OCB } & \multirow{3}{*}{0,200} & 0,026 & 0,980 & 0,577 & 1,733 \\
\hline & KA & & & $-0,610$ & 0,548 & 0,909 & 1,100 \\
\hline & MI & & & $-0,613$ & 0,546 & 0,568 & 1,760 \\
\hline
\end{tabular}

Hasil uji Kolmogorov-Smirnov $\mathrm{Z}$ model regresi pertama adalah sebesar 0,157 dengan Asymp.sig. (2-tailed) 0,75, sedangkan model regresi kedua menghasilkan K-S Z sebesar 0,098 dengan Asymp.sig. (2-tailed) 0,200>0,05 artinya data residual kedua model regresi terdistribusi normal. Hasil uji Glejser model regresi pertama dan kedua pada Tabel 3 menunjukan nilai $\mathrm{t}$ memiliki signifikasi $>0,05$ artinya tidak terjadi heteroskedastisitas pada kedua model regresi. Demikian juga hasil uji multikolonieritas pada Tabel 3 memiliki tolerance $<0,10$ dan VIF $<10$ yang artinya tidak terjadi multikolonieritas.

Tabel 4. Uji Hipotesis

\begin{tabular}{|c|c|c|c|c|c|c|}
\hline \multirow{2}{*}{ Hipotesis } & \multicolumn{2}{|c|}{ Variabel } & \multirow[t]{2}{*}{ Stand. Coeff Beta } & \multirow[b]{2}{*}{$t$} & \multirow{2}{*}{ Sig. } & \multirow{2}{*}{ Adj. R Square } \\
\hline & Bebas & Terikat & & & & \\
\hline H1 & KI & \multirow{2}{*}{ MI } & 0,641 & 4,228 & 0,000 & \multirow[t]{2}{*}{0,386} \\
\hline $\mathrm{H} 2$ & KA & & 0,225 & 1,485 & 0,150 & \\
\hline $\mathrm{H} 3$ & KI & \multirow{3}{*}{ OCB } & $-0,128$ & $-1,171$ & 0,253 & \multirow{3}{*}{0,815} \\
\hline $\mathrm{H} 4$ & KA & & 0,419 & 4,831 & 0,000 & \\
\hline $\mathrm{H} 5$ & MI & & 0,807 & 7,353 & 0,000 & \\
\hline
\end{tabular}

Muhammad Hengki Setiawan1, Prayekti2, I.Soni Kurniawan3 - Faktor Yang Mepengaruhi Organizational Citizenship Behavior ... [Vol 11, No 1 (2020): April 2020] JBTI 
Regresi pertama dengan pengujian $\mathrm{H} 1$ diperoleh nilai t karakteristik individu $(4,228)$, dengan $p$ 0,000/2=0,000 <0,005 atau H1 diterima, sedangkan $\mathrm{H} 2$ diperoleh nilai t komitmen afektif $(1,485)$ dengan nilai $p 0,150 / 2=0,075>0,05$ atau $\mathrm{H} 2$ ditolak. Pada uji regresi kedua diperoleh nilai $\mathrm{t}$ karakteristik individu $(-1,171)$ dengan $p$ 0,253/2=0,1265 >0,05 atau $\mathrm{H} 3$ ditolak; komitmen afektif (4,831) dengan $p$ 0,000/2=0,000 <0,005 atau $\mathrm{H} 4$ diterima; motivasi intrinsik $(7,353)$ dengan $\mathrm{p}$ $0,000 / 2=0,000<0,05$ atau $\mathrm{H} 5$ diterima.

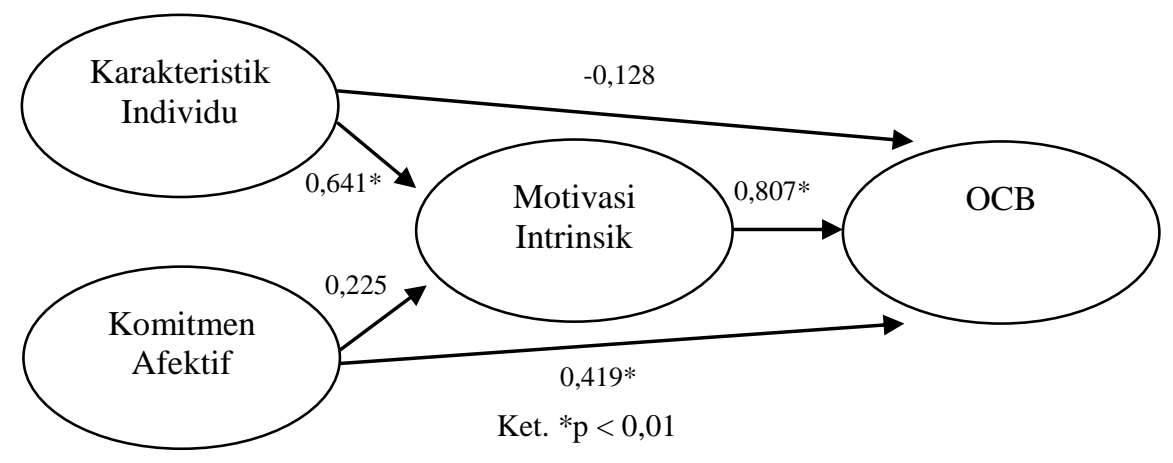

Gambar 1. Model Penelitian

Pengaruh karakteristik individu dan komitmen afektif terhadap motivasi intrinsik memiliki adjusted $R$ square sebesar 0,386 (38,6\%), sisanya 61,4\% disebabkan variabel yang tidak disertakan dalam penelitian ini (Tabel 4). Pengaruh karakteristik individu, komitmen afektif, dan motivasi intrinsik terhadap OCB memiliki nilai adjusted $R$ square sebesar 0,815 (81,5\%), sisanya 18,5\% disebabkan variabel lain yang tidak diuji dalam penelitian ini.

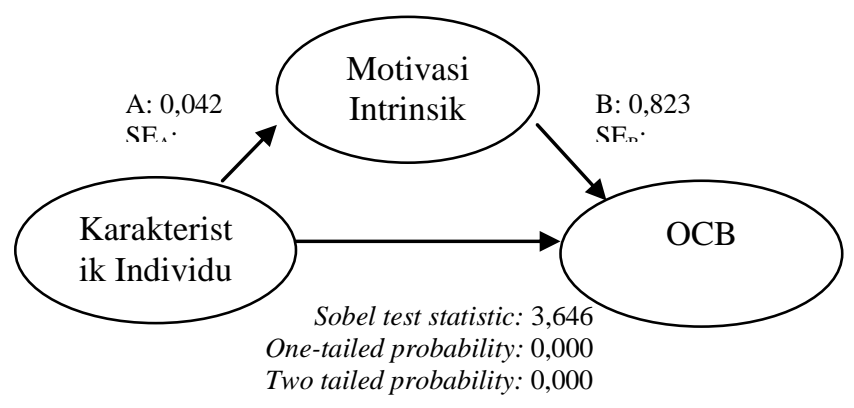

Gambar 2 Hasil Pengujian H6

Pengujian H6 pada Gambar 2 menunjukkan nilai Sobel test $(3,646)$ memiliki nilai one-tail probability $0,000<0,05$ yang artinya motivasi intrinsik memediasi pengaruh karakteristik individu terhadap OCB, atau H6 diterima. Pengujian H7 (Gambar 3) menunjukkan nilai Sobel test $(1,433)$ memiliki nilai one-tail probability $0,076>0,05$ yang artinya motivasi intrinsik tidak memediasi pengaruh komitmen afektif terhadap OCB, atau $\mathrm{H} 7$ ditolak.

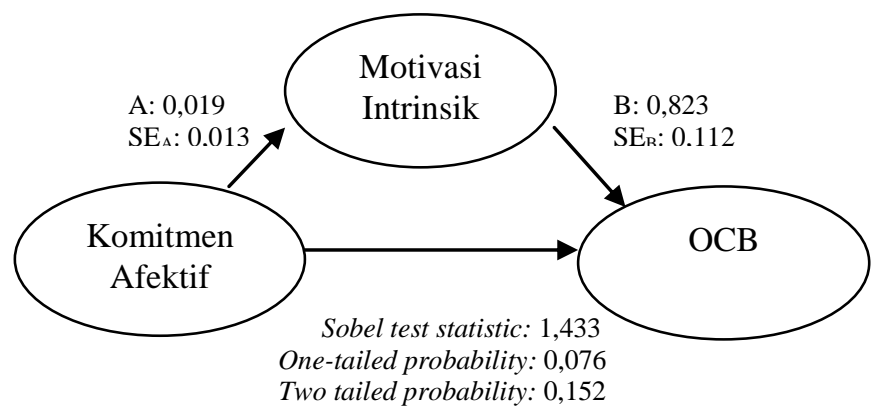

Gambar 3 Hasil Pengujian H7

Muhammad Hengki Setiawan1, Prayekti2, I.Soni Kurniawan3 - Faktor Yang Mepengaruhi Organizational Citizenship Behavior ... [Vol 11, No 1 (2020): April 2020] JBTI 


\section{Pembahasan}

Pengujian hipotesis pertama menunjukkan terdapat pengaruh yang positif dan signifikan dari karakteristik individu terhadap motivasi intrinsik karyawan BUMDes Panggung Lestari. Temuan ini mengkonfirmasi penelitian terdahulu yang dilakukan Major et al. (2006) dan Kridharta \& Rusdianti (2017). Individu dengan karakter extraversion tinggi akan penuh energi, ramah, dan antusias dalam interaksi sosial, serta suka tantangan dalam pekerjaan. Karyawan dengan openness to experience tinggi menunjukkan kemampuannya untuk mudah menyerap informasi baru terkait pekerjaan. Demikian juga bila karyawan memiliki agreeableness tinggi maka menunjukkan semangat untuk bekerja sama melalui sikap kooperatif. Caligiuri (2000) menegaskan dalam risetnya bahwa seorang individu yang memiliki karakteristik ekstroversion, agreeableness, dan emotional stability sebagai bagian big 5 personality berhubungan negatif dengan apakah ekspatriat ingin mengakhiri tugas mereka. Menariknya pada hipotesis ketiga karakteristik individu ditemukan tidak berpengaruh terhadap OCB, yang tidak mengkonfirmasi temuan Benjamin (2012) dan Grego-Planer (2019). Hal ini diduga pengorganisasian BUMDes belum berjalan dengan baik, perlu ada pemahaman yang baik antar karyawan yang berbeda kepribadian mengenai harapan yang harus dicapai pada tiap unit atau departemen. Divisi pemasaran, produksi, keuangan, dan pengembangan SDM harus memiliki tujuan yang jelas, ketidakjelasan membuat kerja sama karyawan dalam organisasi merosot karena factor social loafing. Pengelola perlu juga menyosialisasikan visi misi agar antar karyawan yang berbedabeda karakteristiknya memiliki pemahaman yang terpadu dan keterikatan bersama akan tujuan organisasi yang harus dicapai.

Pengujian hipotesis kedua menunjukkan tidak terdapat pengaruh positif komitmen afektif terhadap motivasi intrinsik pada karyawan BUMDes Panggung Lestari. Penelitian ini tidak sejalan dengan Farida et al., (2016) dan Safrisal (2014) yang menemukan adanya pengaruh positif dan signifikan dari komitmen afektif terhadap motivasi intrinsik. Riset Martin-Cruz (2015) justru menunjukkan arah berkebalikan dimana motivasi intrinsik berpengaruh terhadap komitmen afektif demikian juga dengan Yundong (2015), hal ini perlu diuji lebih lanjut pada penelitian kedepan. Penolakan terhadap hipotesis kedua secara otomatis menghasilkan penolakan terhadap hipotesis ketujuh, motivasi intrinsik tidak memediasi pengaruh komitmen afektif terhadap OCB. Diduga pekerjaan yang tidak sesuai dengan keterampilan individu dan atau tujuan strategik yang tidak dipahami dengan jelas dapat menjadi penyebab komitmen afektif karyawan tidak melahirkan motivasi internal.

Pengujian hipotesis keempat menunjukkan komitmen afektif berpengaruh positif terhadap OCB karyawan, temuan ini mendukung temuan Allen, Evans, \& White (2011) dan Grego-Planer (2019). Komitmen afektif terjadi apabila pegawai merasa bagian dari organisasi, memiliki ikatan emosional, memiliki perasaan bahagia dalam organisasi, dan memiliki arti penting dalam organisasi. Karyawan yang memiliki komitmen akan memiliki sportsmanship (perhatian) dan altruism (perilaku membantu) kepada organisasi. Sikap komitmen karyawan tersebut dapat terbentuk dari dukungan organisasi yang diberikan kepada karyawan, perhatian organisasi dapat berbentuk pemberian pelatihan kerja dan reward terhadap dedikasi karyawan. Pengujian hipotesis kelima menunjukkan terdapat pengaruh yang positif dan signifikan motivasi intrinsik terhadap OCB karyawan BUMDes Panggung Lestari. Karyawan yang memiliki motivasi intrinsik yang tinggi akan memiliki energi dalam diri untuk menyukai pekerjaan yang membentuk sikap OCB. Bentuk sikap OCB karyawan akan memiliki dampak signifikan dalam meningkatkan efektivitas organisasi. Temuan ini sesuai dengan penelitian terdahulu dari Part (2010) dan Ibrahim \& Aslinda (2015).

Pengujian hipotesis keenam menunjukkan motivasi intrinsik memediasi pengaruh karakteristik individu terhadap OCB. Temuan ini mengkonfirmasi gabungan riset Kridharta \& Rusdianti, (2017) dan Ibrahim \& Aslinda (2015) menjadi sebuah model mediasi. Pimpinan BUMDes perlu merekrut karyawan baru atau mengembangkan karyawan lama untuk memiliki sifat

Muhammad Hengki Setiawan1, Prayekti2, I.Soni Kurniawan3 - Faktor Yang Mepengaruhi Organizational Citizenship Behavior ... [Vol 11, No 1 (2020): April 2020] JBTI 
neurotic yang rendah, extraversion (ramah, aktif), openness to experience (terbuka pada pengalaman baru), dan agreeableness (mudah bekerja sama). Memiliki karyawan dengan sifat tersebut akan meningkatkan motivasi intrinsik, dan peningkatan motivasi intrinsik akan mendorong peningkatan dalam OCB. Adanya motivasi intrinsik dalam individu karyawan dapat memicu semangat karyawan bekerja lebih baik, dan bekerja dengan penuh tanggung jawab baik itu tugas utamanya ataupun tugas diluar tanggung jawabnya di organisasi.

\section{KESIMPULAN DAN SARAN}

Temuan penelitian menyatakan bahwa karakteristik individu berpengaruh positif terhadap motivasi internal namun tidak berpengaruh terhadap OCB. Lebih lanjut ditemukan komitmen afektif tidak ditemukan berpengaruh terhadap motivasi internal namun justru berpengaruh positif terhadap OCB. Adanya pengaruh positif motivasi internal terhadap OCB mengakibatkan munculnya peran mediator variabel motivasi internal pada pengaruh karakteristik individu terhadap OCB. Namun motivasi internal bukan pemediator antara komitmen afektif terhadap OCB di BUMDes Panggung Lestari.

Pengelola BUMDes Panggung Lestari perlu memprioritaskan rekrutmen karyawan dengan karakteristik neurotic yang rendah, extraversion yang tinggi, agreeableness yang tinggi, serta openness to experience atau mengarahkan karyawan lama untuk memiliki kepribadian tersebut agar memiliki motivasi internal yang tinggi. Penempatan sesuai karakteristik dan bidang/minat karyawan akan meningkatkan motivasi dan pencapaian kinerja. Motivasi internal juga perlu dikembangkan melalui apresiasi, tugas yang menantang, kerja sama, melibatkan karyawan dalam pengambilan keputusan, serta arahan yang jelas. Motivasi internal dapat memicu OCB dengan karyawan jarang mengeluh, berpartisipasi aktif dalam organisasi, sedia menolong orang lain, dan meringankan masalah pekerjaan karyawan lain. Karyawan dengan OCB tinggi bersedia melaksanakan tugas diluar tanggungjawabnya atau unitnya tanpa mengaitkannya dengan upah, hal ini juga penting karena merupakan cross functional training sukarela. Komitmen afektif perlu didorong melalui penanaman loyalitas dan tanggungjawab serta ikatan emosi dan kepercayaan dalam bekerja terutama pada Tabel 2 sebanyak 80,5\% karyawan menyatakan membutuhkan kreatifitas tinggi dalam pekerjaannya. Penelitian selanjutnya dapat mengembangkan dengan mengaitkan OCB dengan kepuasan kerja dan loyalitas.

\section{DAFTAR PUSTAKA}

Allen, N. J., \& Meyer, J. P. (1990). The measurement and antecedents of affective, continuance and normative commitment to the organization. Journal of Occuptional Psychology, 63(1), 1-18. https://doi.org/https://doi.org/10.1111/j.2044-8325.1990.tb00506.x

Allen, R. S., Evans, W. R., \& White, C. S. (2011). Affective organizational commitment and organizational citizenship behavior: Examining the relationship through the lens of equity sensitivity. Organisation Management Journal, 8(4), 218-228. https://doi.org/10.1057/omj.2011.40

Barabuto Jr., J. E., \& Story, J. S. P. (2012). Work motivation and organizational citiizenship behavior. Journal of Leadership Studies, 5(4), 20-30. https://doi.org/10.1002/jls

Beli, C., \& Njoli, N. (2016). The role of big five factors on predicting job crafting propensities amongst administrative employees in a South African tertiary institution. SA Journal of Human Resource Management, 15(February), 1-11. https://doi.org/10.4102/sajhrm.v14i1.702

Benjamin, A. (2012). The influence of affective commitment on citizenship behavior and intention to quit among commercial banks' employees in Nigeria. Journal of Management and

Muhammad Hengki Setiawan1, Prayekti2, I.Soni Kurniawan3 - Faktor Yang Mepengaruhi Organizational Citizenship Behavior ...

[Vol 11, No 1 (2020): April 2020] JBTI 
Sustainability, 2(2), 54-68. https://doi.org/10.5539/jms.v2n2p54

Bhatti, M. A., Kaur, S., \& Battour, M. M. (2013). Effects of individual characteristics on expatriates' adjustment and job performance. European Journal of Training and Development, 37(6), 544-563. https://doi.org/10.1108/EJTD-02-2013-0013

Caligiuri, P. M. (2000). The big five personality characteristics as predictors of expatriate's desire to terminate the assignment and supervisor-rated performance. Personnel Psychology, 53(1), 67-88. https://doi.org/10.1111/j.1744-6570.2000.tb00194.x

Darsana, M. (2013). The influence of personality and organizational culture on employee performance through organizational citizenship behavior. The International Journal of Management, 35(4), 35-42. https://doi.org/10.4108/eai.12-11-2018.2288817

Dessler, G. (2013). Human Resource Management. New Jersey: Pearson.

Drake, A. R., Wong, J., \& Salter, S. B. (2007). Empowerment motivation, and performance: Examining the impact of feedback and incentives on nonmanagement employees. Behavioral Research in Accounting, 19, 71-89. https://doi.org/10.2308/bria.2007.19.1.71

Farida, S. I., Iqbal, M., \& Kurniasih, A. (2016). Pengaruh kepercayaan dan komitmen organisasi terhadap motivasi dan kepuasan kerja. Jurnal Kependidikan, 46(1), 121-134. https://doi.org/10.21831/jk.v46i1.9576

Grego-Planer, D. (2019). The relationship between organizational commitment and organizational citizenship behaviors in the public and private sectors. Sustainability (Switzerland), 6(6), 120. https://doi.org/10.5897/ajbm11.1216

Hamzah, B. U. (2009). Teori motivasi dan pengukurannya. Jakarta: Bumi Aksara.

Ibrahim, M. A., \& Aslinda. (2015). The effect of motivation on organizational citizenship behavior (OCB) at telkom Indonesia Makassar. Bisnis \& Birokrasi Journal, 21(2), 114-120. https://doi.org/10.20476/jbb.v21i2.4324

Ihsanuddin. (2019). Jokowi dapat laporan 2.188 Badan Usaha Milik Desa tidak beroperasi. Retrieved December 1, 2019, from Kompas.com website: https://nasional.kompas.com/read/2019/12/11/14210741/jokowi- dapat-laporan-2188-badanusaha-milik-desa-tidak-beroperasi.

Jaros, S. (2007). Meyer and allen model of organizational commitment: Measurement issues. Journal of Organizational Behavior, 4(4), 7-26.

Kridharta, D., \& Rusdianti, E. (2017). Analisis pengaruh karakteristik individu, komitmen organisasi, dan kepuasan kerja terhadap kinerja karyawan dengan motivasi sebagai variabel intervening. Jurnal Riset Ekonomi Dan Bisnis, 10(3), 60-76. https://doi.org/10.26623/jreb.v10i3.882

Kurniawan, I. S. (2019). Pengaruh value congruence dan core self-evaluations terhadap job Engagement dan dampaknya pada organizational citizenship behavior. Jurnal Kewirausahaan Dan Bisnis, 23(12). https://doi.org/10.20961/jkb.v23i12.27492

Kurniawan, I. S., \& Hutami, L. T. H. (2019). The mediation of job engagement to rewards and recognition toward organizational citizenship behavior and task performance. 2nd International Conference on Banking, Accounting, Management and Economics, 86(Icobame 2018), 48-52. https://doi.org/10.2991/icobame-18.2019.10

Lee, U. H., Kim, H. K., \& Kim, Y. H. (2013). Determinants of organizational citizenship behavior 
and Its outcomes. Global Business and Mangement Research: An International Journal, 5(1), $54-65$.

Leephaijaroen, S. (2016). Effects of the big-five personality traits and organizational commitments on organizational citizenship behavior of support staff at Ubon Ratchathani Rajabhat University, Thailand. Kasetsart Journal of Social Sciences, 37(2), 104-111. https://doi.org/10.1016/j.kjss.2015.03.002

Major, D. A., Turner, J. E., \& Fletcher, T. D. (2006). Linking proactive personality and the big five to motivation to learn and development activity. Journal of Applied Psychology, 91(4), 927935. https://doi.org/10.1037/0021-9010.91.4.927

Martin-Perez, V., \& Martin-Cruz, N. (2015). The mediating role of affective commitment in the rewards-knowledge transfer relation. Journal of Knowledge Management, 19(6), 1167-1185. https://doi.org/10.1108/JKM-03-2015-0114

Mulyadi, D. Z., Kamaluddin, M., \& Maharani, S. W. (2019). Peran kepuasan kerja dalam memediasi gaya kepemimpinan dan budaya organisasi terhadap komitmen organisasional. Jurnal Manajemen, Bisnis Dan Organisasi (JUMBO), 3(1), 89-102. https://doi.org/10.33772/JUMBO.V3I1.8008

Munajah, A., \& Purba, D. E. (2018). Pengaruh kepemimpinan etis dan iklim Etis terhadap komitmen afektif. Jurnal Psikologi, 14(1), 30-39. https://doi.org/10.24014/jp.v14i1.4456

Murgianto, Sulasmi, S., \& Suhermin. (2016). The effects of commitment, competence, work satisfaction on motivation, and performance of employees at integrated service office of East Java. International Journal of Advanced Research, 3(-), 378-396.

Nazmah, Mariatin, E., \& Supriyantini, S. (2018). Pengaruh iklim organisasi dan keadilan organisasi terhadap organizational citizenship behavior. Analitika: Jurnal Magister Psikologi UMA, 12(3), 33-42. https://doi.org/10.32734/psikologia.v12i3.19835

Nuckcheddy, A. (2018). The effect of personality on motivation and organisational behaviour. Psychology and Behavioral Science International Journal, 9(2), 001-005. https://doi.org/10.19080/pbsij.2018.09.555760

Oren, L., Tziner, A., Nahshon, Y., \& Sharoni, G. (2013). Relations between OCBS, organizational justice, work motivation and self-efficacy. The Protection of Consumer Rights in the Field of Economic Services of General Interest, 14(34), 505-516. https://doi.org/10.18860/mecj.v3i2.7455

Organ, D. W., \& Ryan, K. (1995). A meta-analytic review of attitudinal and dispositional predictors of organizational citizenship behavior. Personnel Psychology, 48(4), 775-802. https://doi.org/10.1111/j.1744-6570.1995.tb01781.x

Part, R. C. (2010). The role of prosocial and intrinsic motivation in employees citizenship behaviour. Baltic Journal of Management, 10(3), 1-5. https://doi.org/10.1108/BJM-05-20140085

Podsakoff, P. M., MacKenzie, S. B., Paine, J. B., \& Bachrach, D. G. (2000). Organizational citizenship behaviors: A critical review of the theoretical and empirical literature and suggestions for future research. Journal of Management, 57(3), 471-473. https://doi.org/10.1016/0009-2614(78)85552-3

Purba, E. D., \& Seniati, A. N. L. (2004). Pengaruh kepribadian dan komitmen organisasi terhadap organizational citizenzhip behavior. Makara, Sosial Humaniora, 8(3), 105-111. 
Puspitasari, S. (2019). Pengaruh kepemimpinan spiritual terhadap kepuasan kerja karyawan melalui motivasi intrinsik dan komitmen organisasi (studi kasus Rumah Sakit Islam Sultan Agung, Semarang). Jurnal Ekonomi Dan Bisnis, 20(1), 73-84. https://doi.org/10.30659/ekobis.20.1.73-84

Ramadhanty, A., \& Kurniawan, I. S. (2020). Penguatan organizational citizenship behavior: Peran kepuasan kerja dan loyalitas. Jurnal Penelitian Ipteks, 5(1), 37-44.

Romaiha, N. R., Maulud, F. S. F., Ismail, W. M. W., Jahya, A., Fahana, N., \& Harun, A. (2019). The determinants of organizational citizenship behaviour (OCB). International Journal of Academic Research in Business and Social Sciences, 9(8), 124-133. https://doi.org/10.6007/IJARBSS/v9-i8/6222

Rothmann, S., \& Coetzer, E. P. (2003). The big five personality dimensions and job performance. SA Journal of Industrial Psychology, 29(1), 68-74. https://doi.org/10.4102/sajip.v29i1.88

Safrizal, S. (2014). Pengaruh kepemimpinan dan komitmen organisasi terhadap motivasi kerja pegawai dan dampaknya pada prestasi kerja Pegawai Sekretariat Dewan Perwakilan Rakyat Aceh (DPRA) (Thesis pada Fakultas Pasca Sarjana Syiah Kuala). Retrieved from https://etd.unsyiah.ac.id/index.php?p=show_detail\&id=6673

Saragih, N. M., Sinulingga, S., \& Siahaan, E. (2019). The influence of individual and work characteristics on organizational citizenship behavior with work culture as moderating variable at PT. Jasa Marga (Persero) Tbk Balmera Branch, Medan. IOSR Journal of Business and Management (IOSR-JBM), 21(1), 47-52. https://doi.org/10.9790/487X-2101024752

Sevilla, C. G. (1960). Research methods. Quezon City: Rex Printing Company.

Wahyudi, D., \& Prawita, S. (2014). Faktor-faktor yang mempengaruhi konsumen dalam memilih sepeda motor Harley Davidson. Jurnal Ilman, 1(1), 83-92. https://doi.org/http://dx.doi.org/10.35126/ilman.v1i1.55

Yundong, H. (2015). Impact of intrinsic motivation on organizational commitment: Empirical evidences from China. International Business and Management, 11(3), 31-44. https://doi.org/10.3968/7723

Zehir, C., Muceldili, B., \& Zehir, S. (2012). The impact of corporate entrepreneurship on organizational citizenship behavior and organizational Commitment: Evidence from Turkey SMEs. 8th International Strategic Management Conference, 58, 924-933. https://doi.org/10.1016/j.sbspro.2012.09.1071

Muhammad Hengki Setiawan1, Prayekti2, I.Soni Kurniawan3 - Faktor Yang Mepengaruhi Organizational Citizenship Behavior ... [Vol 11, No 1 (2020): April 2020] JBTI 